\title{
REPRESENTASI PEMBERITAAN PEMULANGAN EKS GAFATAR RIAU DI SURAT KABAR RIAU POS
}

\author{
Chelsy Yesicha, Suyanto, Belli Nasution \\ Program Studi Ilmu Komunikasi Universitas Riau \\ Email: chelsy.yesicha@lecturer.unri.ac.id, suyantomsc@gmail.com, belli.nasution@yahoo.com
}

\begin{abstract}
The research was distributed by the author's interest against Ex Gafatar that occur in Indonesia. Their existence as illegal organization until their expulsion from Earth borneo makes compelling colors for covered by the various media. Each media pack with news of construction in accordance with the ideology they have. So, researchers specializing in the preaching of the Riau Post as local media in spreading the repatriation of Ex Gafatar to Riau. This study used a qualitative approach to discourse analysis models Teun A Van Dijk. Data was collected by interview and documentation. The object of ten research news, consists of nine news from Riau. Informants consisted from chief editor Riau Pos's newspaper. To achieve the validity of the data in this research, researchers used triangulation. The results showed: first, Analysis of the discourse, news coverage in newspapers the Riau Post puts a theme raised about the handling of the journey undertaken by the Government of Riau in escorting the repatriation of ex gafatar to Riau. The emphasis on the performance of the apparatus of Government through the promised construction of the Riau Post attempted to grow back the trust of the community to be able to accept back those in neighborhoods with a guarantee from the Government. Second, Representation of the media conducted by the Riau post which uses a constructionist approach is judged in favour to the Government as a form of fostering kepercayaaan Government in dealing with such cases. Without these events, hide impressed the Riau Post tried to suppress the conflict by giving the role of social control to the public.
\end{abstract}

Keyword: Representation, Discourse analysis, News Construction

\section{LATAR BELAKANG}

Setelah dikabarkan hilang sejak 30 Desember 2015, Dokter Rica Tri Handayani bersama bayinya ini diketahui sudah lama bergabung dengan organisasi terlarang Gerakan Fajar Nusantara (Gafatar). Sejak itu mulai bermunculan beberapa orang yang dilaporkan hilang dari berbagai daerah dan dicurigai bergabung dengan kelompok tersebut. Media pun tak henti-hentinya melaporkan perkembangan berita kelompok tersebut. Hingga pada akhirnya diketahui sebagian besar anggota Gafatar telah bermukim di Kubu Raya, Kalimantan Barat.

Mata media semakin aktif tertuju pada Gafatar Kalbar namun hal tersebut justru memberikan kecemasan pada masyarakat yang hingg terjadilah pengusiran mereka dari tanah Kalimantan Barat. Berita gafatar cukup membangunkan perhatian sosial politik bangsa karena organisasi ini dianggap menganggu stabilitas keamanan negara. Meskipun organisasi gafatar dibubarkan sejak tahun 2015 secara nasional oleh ulama karena dianggap aliran sesat.

Tak terkecuali media Riau Pos, harian pagi Riau Pos yang membuktikan diri sebagai salah satu koran terkemuka di Sumatera dan baru saja berhasil meraih penghargaan Gold Winner Indonesia Print Media Award (IPMA) 2016, turut menyajikan perkembangan berita Gafatar. Hal ini bukan saja karena gafatar menjadi berita nasional namun dikarenakan terdapat warga Riau yang juga anggota gafatar. Merekapun memiliki nasib yang sama dengan seperti anggota eks Gafatar yang lain yaitu dipulangkan kembali ke kampung halaman. Hal ini tidaklah mudah bagi pemerintah 
dimana banyak persoalan yang muncul mulai dari dana, ajaran yang mereka anut hingga penolakan bagi masyarakat terhadap kehadiran mereka di kampung halamannya. Tentu saja semua pihak tidak menginginkan kerusuhan atau penolakan yang juga terjadi di Riau.

Berkaitan dengan fenomena diatas media memiliki peran penting dalam menyampaikan informasinya. Efektifitas komunikasipun diperlukan agar tidak menimbulkan miscommunication bahkan konflik SARA. Di sisi lain, media tidak semua media dapat menjalankan fungsi mereka dengan baik. Ada juga media memiliki kepentingan politik sesaat atau media yang betul-betul serius untuk menjalankan sebuah bisnis. Hal ini dapat terlihat dari masingmasing media massa dengan ciri khas (ideologi) mereka tersendiri yang tergambar mulai dari fokus pemberitaan, bentuk atau tata letak (Lay-out) pada sampul, bentuk tulisan, pengunaan bahasa, warna (cover dan headlines), bahkan ukuran media cetak itu sendiri. Ciri khas ini selalu dijaga dengan konsisten dengan tujuan, khalayak media langsung bisa mengenali yang ia konsumsi. Ciri khas media ini juga mengambarkan arah dan tujuan dari media itu didirikan.

Maka identifikasi masalah yang akan dikemukakan dalam penelitian ini adalah; Bagaimana analisis wacana Van Dijk pemberitaan pemulangan eks gafatar di surat kabar Riau Pos? Bagaimana representasi yang dibentuk dalam pemberitaan pemulangan eks gafatar di surat kabar Riau Pos?

Berdasarkan perioditasnya, surat kabar yang diteliti dalam penelitian ini adalah Surat Kabar Harian (SKH). Surat kabar harian adalah jenis media cetak yang terbit setiap hari, kecuali pada hari-hari tertentu, misalnya libur nasional. Jenis surat kabar ini dibagi lagi menjadi surat kabar harian nasional, surat kabar harian daerah, dan surat kabar harian lokal. Berita yang disampaikan adalah informasi terkini dan disampaikan dengan sistem straight news atau apa adanya.

Sebagai media yang memiliki fungsi informasi, mendidik, mempengaruhi (persuade) dan menghibur, media selalu mengkampanyekan dirinya sebagai media yang independen dan berpihak kepada khalayak ramai. Namun sesungguhnya tidak ada media yang benar-benar bebas. Media itu tidak objektif tapi subjektif yang memungkinkan informasi yang disajikannya adalah bias. Hal ini disebabkan, dalam memberitakan satu peristiwa, media dengan mengacu pada kedah penulisan jurnalistik yang singkat, padat, dan kalimat yang sederhana atau mudah dimengerti, seorang reporter tidak akan mampu menyajikan informasi yang menyeluruh tentang peristiwa yang diliputnya.

Althusser (dalam Sobur, 2006:30) menjelaskan media dalam hubunganya dengan kekuasaannya, menempati posisi strategis terutama karena kemampuannya sebagai sarana legitimasi. Media sebagaimana lembaga-lembaga lainnya, merupakan bagian dari alat kekuasaan negara yang bekerja secara ideologis guna membagun kepatuhan khalayak terhadap kelompok yang berkuasa.

Sementara itu, Gramsci (dalam Sobur, 2006:30) melihat media sebagai ruang di mana berbagai ideologi direpresentasikan. Di satu sisi, media berfungsi sebagai sarana penyebaran ideologi penguasaan, alat legitimasi, dan kontrol atas wacana publik. Namun, di sisi lain media bisa menjadi alat pembangunan budaya dan ideologi yang sangat berpengaruh bagi kepentingan penguasa sekaligus menjadi alat perjuangan kaum tertindas membagun kultur dan ideologi tandingan.

Teori Representasi (Theory of Representation) yang dikemukanan oleh Stuart Hall (1997) menjadi teori utama yang melandasi penelitian ini. Pemahaman utama dari teori representasi adalah penggunaan bahasa (language) untuk menyampaikan sesuatu yang berarti meaningful) kepada orang lain. Representasi adalah bagian terpenting dari proses dimana arti (meaning) diproduksi dan dipertukarkan antara anggota kelompok dalam sebuah kebudayaan (culture). 
Representasi adalah mengartikan konsep (concept) yang ada di pikiran kita dengan menggunakan bahasa. (Hasfi; 2011:35)

Struat Hall (1997) secara tegas mengartikan representasi sebagai proses produksi arti dengan menggunakan bahasa. Sementara the Shorter Oxford English Dictionari (dalam Struat Hall; 1997: 16) membuat dua pengertian yang relevan yaitu:

- Merepresentasikan sesuatu adalah mendeskripsikannya, memunculkan gambaran atau imajinasi dalam benak kita, menempatkan kemiripan dari obyek dalam pikiran/ indera kita, seperti dalam kalimat ini; 'Foto ini merepresentasikan pembunuhan Abel oleh Cain'.

- Merepresentasikan sesuatu adalah menyimbolkan, mencontohkan, menempatkan sesuatu, penggantikan sesuatu, seperti dalam kalimat ini; bagi umat Kristen, Salib merepresentasikan penderitaan dan penyalipan Yesus.

Teori representasi sendiri dibagi dalam tiga teori atau pendekatan yaitu ; (1) reflective approach yang menjelaskan bahwa bahasa berfungsi seperti cermin yang merefleksikan arti yang sebenarnya. Di abad ke-4 SM, bangsa Yunani mengistilahkannya sebagai mimetic. Misalnya, mawar ya berarti mawar, tidak ada arti lain.(2) Intentional approach, dimana bahasa digunakan mengekspresikan arti personal dari seseorang penulis, pelukis, dll. Pendekatan ini memiliki kelemahan, karena menganggap bahasa sebagai permainan privat (private games) sementara disisi lain menyebutkan bahwa esensi bahasa adalah berkomunikasi didasarkan pada kode-kode yang telah menjadi konvensi di masyarakat bukan kode pribadi. (3) Constructionist approach yaitu pendekatan yang menggunakan sistem bahasa (language) atau sistem apapun untuk merepresentasikan konsep kita (concept). (Hasfi, 2011:52)

Pendekatan ini tidak berarti bahwa kita mengkonstruksi arti (meaning) dengan menggunakan sistem representasi (concept dan signs), namun lebih pada pendekatan yang bertujuan mengartikan suatu bahasa (language). Contoh model ke-3 adalah Semiotic approach yang dipengaruhi oleh ahli bahasa dari Swiss, Ferdinand de Saussure dan Discursive approach oleh filosof Perancis bernama Micheal Foucault.

Meskipun pendekatan constructionist approach menjadi dasar pemikiran penelitian ini, namun pendekatan semiotic dan discursive tidak digunakan dalam penelitian ini karena metode yang digunakan adalah framing. Relevansi utama dari teori konstruktionist terhadap penelitian adalah tentang penjelasan bahwa bahasa (language) yang terdapat dalam berita berupa kumpulan dari signs (artikel, foto, video, kalimat) memiliki arti (meaning) yang merepresentasikan budaya (culture) yang ada di masyarakat kita, termasuk media.

\section{Gambar. 1.2. Alur Representation System Process}

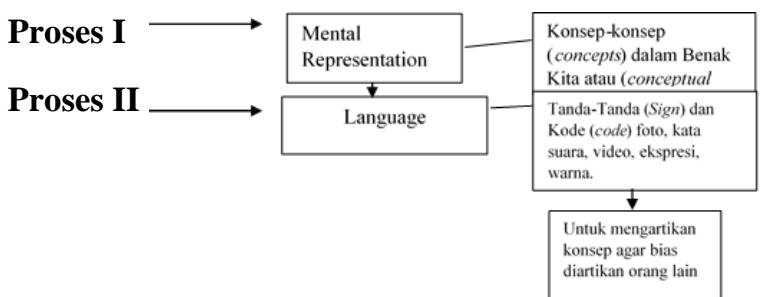

Sumber : Stuart Hall,1997 (dalam Nurul Hasfi: 2011: 104)

Hall menyebutnya sebagai 'sistem' karena proses ini tidak hanya melibatkan konsep yang dimiliki individu, namun juga meliputi konsep-konsep yang diorganisir, dikelompokkan, disusun dan diklasifikasikan secara berbeda yang menghasilkan hubungan yang kompleks diantara konsep-konsep tersebut.

\section{METODE PENELITIAN}

Analisis wacana merupakan salah satu pisau analisis teks media. Berdasarkan level konseptual teoritis, wacana diartikan sebagai domain umum dari semua pernyataan, yaitu semua ujaran atau teks yang mempunyai makna dan mempunyai efek dalam dunia nyata. Sementara, dalam konteks penggunaannya, wacana berarti sekumpulan 
pernyataan yang dapat dikelompokkan ke dalam kategori konseptual tertentu. Pengertian ini menekankan pada upaya untuk mengidentifikasi struktur tertentu dalam wacana, yaitu kelompok ujaran yang diatur dengan suatu cara tertentu (Sobur, 2006:11).

Model analisis wacana yang peneliti gunakan dalam penelitian ini adalah model yang dikembangkan oleh Teun A Van Dijk. Menurut Van Dijk wacana digambarkan mempunyai tiga dimensi yaitu teks, kognisi sosial dan konteks sosial. Dalam dimensi teks yang diteliti adalah bagaimana struktur teks dan strategi wacana yang dipakai untuk menegaskan suatu tema tertentu. Pada level kognisi sosial dipelajari proses produksi teks berita yang melibatkan kognisi individu dari wartawan. Sementara itu aspek konteks sosial mempelajari bangunan wacana yang berkembang dalam suatu masyarakat akan suatu masalah (Eriyanto, 2011:224).

Model analisis Van Dijk dapat digambarkan seperti dibawah ini:

Gambar 2.1 Model Analisis Wacana Van Djik

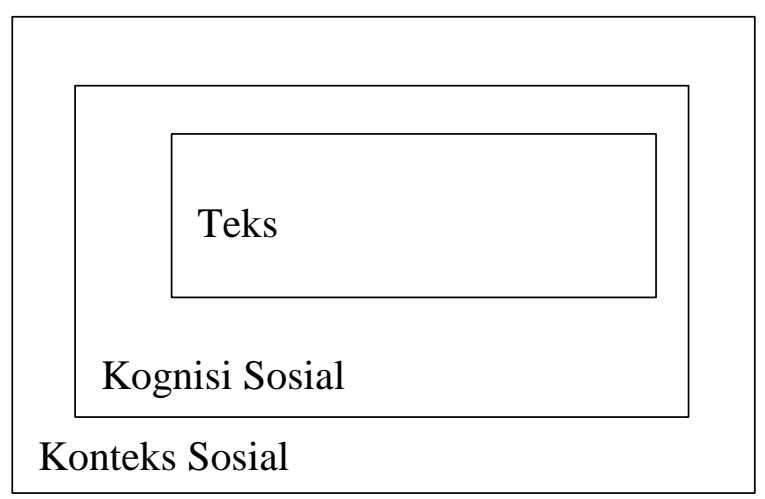

Sumber: Eriyanto, 2011:225

Skema penelitian dan metode yang bisa dilakukan dalam kerangka Van Dijk sebagai yang digunakan dalam menganalisa data :

Tabel 2.2. Skema Wacana Van Dijk

\begin{tabular}{|c|c|}
\hline Struktur & Metode \\
\hline $\begin{array}{l}\text { Teks } \\
\text { Menganalisis bagaimana } \\
\text { wacana yang dipakai untuk } \\
\text { menggambarkan seseorang atau } \\
\text { peristiwa tertentu. Bagaimana } \\
\text { strategi tekstual yang dipakai } \\
\text { untuk menyingkirkan atau } \\
\text { memarginalkan } \\
\text { kelompok, gagasan atau } \\
\text { perirtiwa tertentu }\end{array}$ & $\begin{array}{l}\text { Critical } \\
\text { Linguistik }\end{array}$ \\
\hline $\begin{array}{l}\text { Kognisi social } \\
\text { Menganalisis bagaimana } \\
\text { kognisi wartawan dalam } \\
\text { memahami seseorang atau } \\
\text { peristiwa tertentu yang akan } \\
\text { ditulis }\end{array}$ & $\begin{array}{l}\text { Wawancara } \\
\text { mendalam }\end{array}$ \\
\hline $\begin{array}{l}\text { Konteks social } \\
\text { Menganalisis bagaimana } \\
\text { wacana yang berkembang } \\
\text { dalam masyarakat, proses } \\
\text { produksi dan reproduksi atau } \\
\text { peristiwa digambarkan }\end{array}$ & $\begin{array}{l}\text { Studi } \\
\text { pustaka, } \\
\text { penelusuran } \\
\text { sejarah }\end{array}$ \\
\hline
\end{tabular}

Sumber: Eriyanto, 2011:275

Dalam dimensi teks, yang diteliti adalah struktur dari teks. Pada analisis ini, Van Dijk melihat suatu teks terdiri dari beberapa struktur/tingkatan yang masing-masing bagian saling mendukung. Van Dijk membuat kerangka analisis wacana yang dapat digunakan untuk melihat suatu wacana teks yang terdiri dari berbagai tingkatan atau struktur teks. Van Dijk membaginya ke dalam tiga tingkatan yaitu: 
Tabel 2.3 Struktur Wacana Teks Van Dijk

\begin{tabular}{|c|}
\hline Struktur Makro \\
$\begin{array}{c}\text { Makna global dari suatu teks yang dapat } \\
\text { diamati dari topik/tema yang diangkat } \\
\text { oleh suatu teks. }\end{array}$ \\
Superstruktur \\
Kerangka suatu teks, seperti bagian \\
pendahuluan, isi, penutup, dan \\
kesimpulan.
\end{tabular}

Sumber: Eriyanto, 2011:227
Pemakaian kata, kalimat, proposisi, retorika tertentu oleh media dipahami Van Dijk sebagai bagian dari strategi wartawan. Pemakaian kata-kata tertentu, kalimat, gaya tertentu bukan semata-mata dipandang sebagai cara berkomunikasi, tetapi dipandang sebagai politik berkomunikasi. Struktur wacana adalah cara yang efektif untuk melihat proses retorika dan persuasi yang dijalankan ketika seseorang menyampaikan pesan. Kata-kata tertentu mungkin dipilih untuk mempertegas pilihan dan sikap, membentuk kesadaran politik, dan sebagainya. Struktur atau elemen wacana teks yang dikemukakan Van Dijk dapat digambarkan sebagai berikut:

Berdasarkan model analisis wacana teks Van Dijk tersebut, maka dapat dibuat kerangka berfikir yang diharapkan dapat dijelaskan sebagai berikut:

\section{Gambar 2.3 Kerangka Pemikiran}

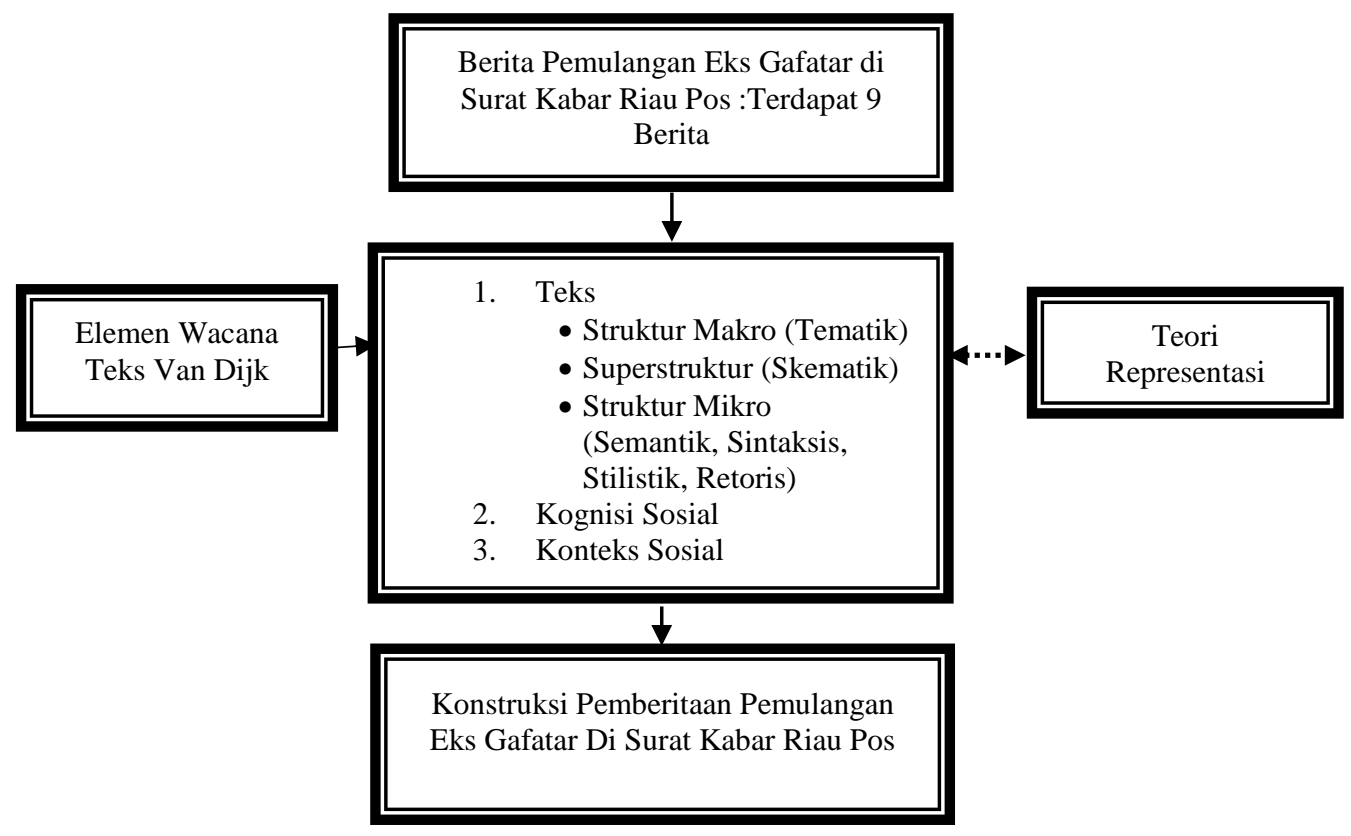

Sumber : Olahan Peneliti, 2016

Data primer dalam penelitian ini adalah liputan berita dari Riau Pos mulai dari tanggal 22 Januari 2016 -11 Febuari 2016. Data sekunder yaitu data yang diperoleh dari instansi perusahaan guna mendukung pembahasan pada penelitian ini data sekunder yang digunakan adalah hasil wawancara dengan Pimpinan redaksi Riau Pos dan studi kepustakaan yang kemudian diolah oleh peneliti untuk dianalisis.

Yang menjadi objek penelitian dalam hal ini adalah pemberitaan pemulangan Eks gafatar Riau di media Riau Pos. Berikut merupakan tabel unit analisis ; 
Tabel 2.4 Unit Analisis

\begin{tabular}{|c|c|c|c|}
\hline No & Kolom & Tanggal & Judul \\
\hline 1 & Nasional & $\begin{array}{c}\text { Jumat, } 22 \\
\text { Januari } 2016\end{array}$ & $\begin{array}{c}\text { Gafatar Sempat } \\
\text { Jelajahi } \\
\text { Pelalawan }\end{array}$ \\
\hline 2 & Nasional & $\begin{array}{c}\text { Rabu, } 27 \\
\text { Januari } 2016\end{array}$ & $\begin{array}{l}13 \text { Warga Riau } \\
\text { Eks Gafatar } \\
\text { Dipulangkan }\end{array}$ \\
\hline 3 & Nasional & $\begin{array}{c}\text { Kamis, } 28 \\
\text { Januari } 2016\end{array}$ & $\begin{array}{l}\text { Eks Gafatar } \\
\text { Riau Enggan } \\
\text { Dipulangkan }\end{array}$ \\
\hline 4 & Headline & $\begin{array}{c}\text { Sabtu, } 30 \\
\text { Januari } 2016\end{array}$ & $\begin{array}{c}\text { Tidak Mungkin } \\
\text { Kami Disia- } \\
\text { siakan Eks } \\
\text { Gafatar Riau } \\
\text { Terdata } 123 \\
\text { Orang }\end{array}$ \\
\hline 5 & $\begin{array}{c}\text { Pro } \\
\text { Otonomi }\end{array}$ & $\begin{array}{c}\text { Selasa, } 2 \\
\text { Febuari } 2016\end{array}$ & $\begin{array}{c}252 \text { Mantan } \\
\text { Gafatar Riau } \\
\text { Tunggu } \\
\text { Dipulangkan }\end{array}$ \\
\hline 6 & Nasional & $\begin{array}{c}\text { Kamis, } 4 \\
\text { Febuari } 2016 \\
\end{array}$ & $\begin{array}{l}\text { Pemprov } \\
\text { Kesulitan }\end{array}$ \\
\hline
\end{tabular}

\begin{tabular}{|c|c|c|c|}
\hline & & & $\begin{array}{c}\text { Pulangkan 135 } \\
\text { Warga Riau Eks } \\
\text { Gafatar }\end{array}$ \\
\hline 7 & Headline & $\begin{array}{c}\text { Selasa, 9 } \\
\text { Febuari 2016 } \\
\text { "Islam Anda } \\
\text { dan Saya Beda" }\end{array}$ \\
\hline 8 & Headline & $\begin{array}{c}\text { Rabu, 10 } \\
\text { Febuari 2016 }\end{array}$ & $\begin{array}{c}\text { Eks Gafatar } \\
\text { Dijaga Ketat }\end{array}$ \\
\hline 9 & Pro & Kamis, 11 & $\begin{array}{c}\text { Eks Anggota } \\
\text { Gafatar } \\
\text { Diberikan } \\
\text { Berbagai Materi }\end{array}$ \\
\hline
\end{tabular}

\section{HASIL PENELITIAN}

\section{Hasil Analisis Wacana Van Dijk}

Berdasarkan pembahasan diatas maka dapat dapat peneliti simpulkan hasil analisis struktur atau elemen wacana teks yang dikemukakan Van Dijk dapat digambarkan sebagai berikut:

Tabel 3.1 Hasil Analisis Wacana Teks Van Dijk Olahan Peneliti

\begin{tabular}{|c|c|c|c|}
\hline $\begin{array}{c}\text { Struktur } \\
\text { wacana }\end{array}$ & Hal yang diamati & Elemen & Analisis \\
\hline $\begin{array}{c}\text { Struktur } \\
\text { makro }\end{array}$ & $\begin{array}{l}\text { Tematik } \\
\text { (Apa yang dikatakan dari } \\
\text { wacana pemulangan eks } \\
\text { Gafatar di surat Kabar } \\
\text { Riau Pos?) }\end{array}$ & Topik & $\begin{array}{l}\text { Secara tematik, judul yang digunakan oleh } \\
\text { Riau Pos selalu jelas mengambarkan apa } \\
\text { yang semenjadi liputannya. Kecenderungan } \\
\text { yang dilakukan adalah mengutip pernyatan } \\
\text { dari narasumber baik itu dari pihak } \\
\text { pemerintah maupun eks Gafatar. }\end{array}$ \\
\hline Superstruktur & \begin{tabular}{l}
\multicolumn{2}{c|}{ Skematik } \\
(Bagaimana pendapat \\
disusun dan dirangkai \\
dari wacana pemulangan \\
eks Gafatar di surat \\
kabar Riau Pos?)
\end{tabular} & Skema & $\begin{array}{l}\text { Pemberitaan pemulangan warga Riau eks } \\
\text { gafatar tetap menjadi tanggungjawab media } \\
\text { dalam menyajikan informasi ini. Riau Pos } \\
\text { selalu memberikan angle pada kesulitan, } \\
\text { tindakan dan upaya pemerintah. Namun } \\
\text { pasca pemulangan Riau Pos mulai } \\
\text { menyeimbangkannya dengan pernyataan } \\
\text { dari anggota eks gafatar terhadap harapan } \\
\text { dan pengalaman mereka. }\end{array}$ \\
\hline $\begin{array}{c}\text { Struktur } \\
\text { Mikro }\end{array}$ & $\begin{array}{l}\text { Semantik } \\
\text { (Makna yang ingin } \\
\text { ditekankan dalam teks } \\
\text { berita dari wacana } \\
\text { pemulangan eks Gafatar } \\
\text { di surat kabar Riau Pos?) }\end{array}$ & $\begin{array}{l}\text { Latar, } \\
\text { detail, } \\
\text { maksud, } \\
\text { pra } \\
\text { anggapan, } \\
\text { nominalis } \\
\text { asi }\end{array}$ & $\begin{array}{l}\text { Secara implisit, elemen semantik Riau Pos } \\
\text { dalam memberitakan Pemulangan eks } \\
\text { Gafatar lebih didominasi dengan } \\
\text { menguraikan fakta yang dilakukan oleh } \\
\text { pemerintah. Sehingga terlihat keterpihakan } \\
\text { media terhadap pemerintah. Pra anggapan } \\
\text { sangat sering digunakan sebagai harapan } \\
\text { dan proyeksi terutama dari ajaran yang }\end{array}$ \\
\hline
\end{tabular}




\begin{tabular}{|c|c|c|}
\hline & & $\begin{array}{l}\text { mereka anut karena hal tersebut menjadi } \\
\text { sebuah penyimpangan bahkan ancaman } \\
\text { terhadap stabilitas negara. Ini cernerung } \\
\text { disampaikan di setiap berita oleh tokoh- } \\
\text { tokoh pemerintah yang menjadi narasumber } \\
\text { sebagai bentuk antisipasi. Dari sembilan } \\
\text { berita hanya satu berita saja yang tidak } \\
\text { terdapat elemen nominalisasi. Umumnya hal } \\
\text { tersebut terkait kepastian jumlah eks gafatar } \\
\text { dan anggaran pemulangan. }\end{array}$ \\
\hline $\begin{array}{l}\text { Sintaksis } \\
\text { (Bagaimana pendapat } \\
\text { disampaikan dari } \\
\text { wacana pemulangan eks } \\
\text { Gafatar di surat kabar } \\
\text { Riau Pos?) }\end{array}$ & $\begin{array}{c}\text { Bentuk } \\
\text { kalimat, } \\
\text { koherensi, } \\
\text { kata ganti }\end{array}$ & $\begin{array}{l}\text { Elemen sintaksis yang diuraikan lebih } \\
\text { menggambarkan keadaan yang terjadi pada } \\
\text { saat peristiwa terutama pada pengungsi eks } \\
\text { gafatar maupun kesibukan pemerintah } \\
\text { dalam mencari solusi penangan kasus ini. } \\
\text { Analisis kata ganti lebih banyak } \\
\text { menggunakan kata 'mereka' yang } \\
\text { menunjukkan bahwa warga Riau eks gafatar } \\
\text { ini dalap dilihat dari pendapat sumber } \\
\text { kutipan dan pihak media juga memiliki } \\
\text { persepsi yang sama selaku komunikator } \\
\text { pesan. Hail ini juga menunjukkan bahwa eks } \\
\text { gafatar sebagai subjek memegang peranan } \\
\text { penting pemberitaan tersebut. }\end{array}$ \\
\hline $\begin{array}{l}\text { Stilistik } \\
\text { (Pilihan kata apa yang } \\
\text { dipakai dari wacana } \\
\text { pemulangan eks Gafatar } \\
\text { di surat kabar Riau Pos?) }\end{array}$ & Leksikon & $\begin{array}{l}\text { Elemen Leksikon yang terdapat di } \\
\text { pemberitaan Riau Pos terkait kasus ini } \\
\text { banyak kata-kata yang digunakan lebih } \\
\text { cenderung kata yang bisa dipakai sehari-hari } \\
\text { seperti 'meneken', 'duduk bersama' } \\
\text { sehingga pembaca lebih mudah mengerti. }\end{array}$ \\
\hline $\begin{array}{l}\text { Retoris } \\
\text { (Bagaimana dan dengan } \\
\text { cara apa penekanan } \\
\text { dilakukan dari wacana } \\
\text { pemulangan eks Gafatar } \\
\text { di surat kabar Riau Pos?) }\end{array}$ & $\begin{array}{l}\text { Grafis, } \\
\text { metafora, }\end{array}$ & $\begin{array}{l}\text { Jika ditinjau dari elemen retorisnya, berita } \\
\text { ini jarang menjadi Headline meski hanya } \\
\text { dua edisi yang menjadi headline dari } \\
\text { sembilan berita yang diteliti oleh peneliti. } \\
\text { Penempatannya lebih dominan dalam kolom } \\
\text { Nasional. Setiap berita minim foto peristiwa } \\
\text { dan cenderung menampilkan foto close up } \\
\text { tokoh pejabat pemerintah yang berwenang } \\
\text { terhadap peristiwa tersebut untuk } \\
\text { melengkapi kelengkapan informasi sehingga } \\
\text { berita kurang mendapat perhatian pembaca. } \\
\text { Untuk metafora, beberapa kali digunakan } \\
\text { untuk menggambarkan kondisi subyek. } \\
\text { Apalagi pada saat yang sama terjadi banjir di } \\
\text { kabupaten Kampar yang dinilai memiliki } \\
\text { news value lebih dibandingkan dengan } \\
\text { pemberitaan eks gafatar. }\end{array}$ \\
\hline
\end{tabular}

Sumber: Eriyanto, 2011:228-229 
Analisis kognisi sosial dalam pemberitaan pemulangan warga eks Gafatar di surat kabar Riau Pos. Ideologi Riau Pos dalam menyajikan berita untuk khalayak sesuai dengan tagline mereka yaitu "Bangun Negeri Bijakkan Bangsa", Riau Pos Lebih mengutamakan untuk menjaga marwah Riau, sebagai media cetak ternama di Riau. Asmawi selaku Pimpinan Redaksi menyatakan Riau Pos juga menyebutkan bergerak sebagai jurnalisme akomodatif.

"Dalam hal ini, kami memberikan informasi sesuai dengan apa yang di nyatakan oleh pemerintah. Dalam kasus pemulangan warga Riau eks gafatar menjadi memang sudah menjadi perhatian nasional dan sudah berulang-ulang. Apalagi saat ini kasus tersebut sudah ditangani oleh Kementrian Agama. Penempatan berita dilakukan karena pertimbangan sesuai dengan tanggungjawab pemerintah dan kasus besar yang saat itu terjadi di Kabupaten Kampar. Ini menjadi perhatian lebih baik dari human interest maupun proximity." (wawancara 28 Juni 2016)

Redaksi memiliki peran dalam mengkontruksikan/memfilter beritanya tapi ini baginya adalah hal yang wajar dalam dapur media pers cetak. Riau Pos dalam hal melaksanakan kegiatan jurnalistik masih memegang teguh prinsip prinsip menjaga marwah negerinya yaitu Riau. Tak terkecuali dalam kasus pemulangan Eks gafatar, Riau Pos dalam menyajikan beritanya menyampaikan pemerintah telah melakukan hal yang semestinya seperti memfasilitasi kepulangan hingga melakukan pembinaan terhadap mereka. Semua ini dilakukan agar ajaran yang menyimpang tidak hidup lagi dalam diri mereka dan masyarakat bisa menerima mereka kembali ke kampung halaman dengan rasa aman. Riau Pos merasa tidak perlu menyembunyikan hal atau peristiwa apapun dari masyarakat namun mereka lebih banyak memperhalus dan menyamarkan kata terutama dalam judul. Berita yang disampaikan memang sesuai dengan kenyataannya namun mereka lebih menyanjung prinsip wisdom yang tertanam dalam ideologi mereka.

Sebagai media terbesar lokal yang ada di Riau, Riau Pos memiliki peran untuk menjaga daerah dan hal yang dipaparkan diatas tersebut merupakan salah satu wujud nyata yang dapat mereka lakukan sebagai peran mereka sebagai media yaitu kontrol sosial. Menjaga citra pemerintah sekaligus negeri sesuai dengan yang terkandung dalam misi mereka "Bangun Negeri Bijakkan Bangsa".

Analisis konteks sosial pemberitaan pemulangan warga eks Gafatar di yang ditemukan sesuai dengan pemberitaan diatas,Eks gafatar riau yang berjumlah 50 orang menjadi pertimbangan akan memiliki dampak besar walaupun angka 50 itu masih sangat minim jika dibandingkan dengan jumlah populasi masyarakat Riau saat ini. Ajaran menyimpang yang disebarkan oleh Ahmad Musadek ini bisa saja tumbuh dan menjamur kembali.

Meski dianggap telah dibubarkan namun kita perlu waspadai tumbuhnya kembali organisasi-organisasi menyimpang ini. Menurut Mukhtarudin Guru SMAN 1 Tebing Tinggi Kabupaten Kepulauan Meranti, keberadaan organisasi maupun aliran sesat sebenarnya bisa dideteksi sejak dini oleh masyarakat sekitar, masyarakat harus berperan aktif memonitoring aliran-aliran, dan organisasi yang sedang berkembang di kalangan masyarakat itu sendiri.
"Waspadailah aliran dan organisasi yang ada di sekitar kita, dan ini tentunya memiliki dampak, tak hanya bagi agama, tapi juga masyarakat dan bahkan bangsa. Dari segi keagamaan, jika memang terbukti benarini hanya metamorfosis dari Al-Qiyadah Al- Islamiyyah pimpinan Ahmad Moshaddeq, maka gerakan ini jelas 
sesat, karena mengakui ada nabi setelah Muhammad. Dari segi sosial, gerakan ini jelas meresahkan karena membuat pengikutnya harus menjual harta benda dan rumahnya untuk pindah ke tempat asing (Kalimantan) untuk menyempurnakan ajaran "agama" sesuai arahan pimpinan Gafatar. Secara politik, gerakan ini berbahaya, karena Kapolri sendiri pernah menyampaikan mereka punya niat membuat negara sendiri. Gerakan-gerakan seperti ini memang bisa saja terus ada dan bergerak liar jika tak ada deteksi dini, kewaspadaan bersama, dan antisipasi semua pihak."(Opini Epaper Riau Pos, Jumat, 29 Januari 2016)

Gafatar merupakan aliran ajaran agama islam yang telah ditetapkan menyimpang oleh MUI. Dikutip dari tulisan Masrizal Al Husyaini, Dai Ikmi Kota Pekanbaru Alumnus Pondok Pesantren Musthafawiyah Purba Baru untuk menetapkan suatu aliran menyimpang melalui fatwanya Majelis Ulama Indonesia (MUI) dalam Rakernas tahun 2007 terdapat 10 ketentuan yang digunakan untuk menetapakan suatu aliran sesat atau tidaknya yaitu;

"Pertama, mengingkari salah satu rukun Islam dan rukun Iman. Kedua, meyakini turunnya wahyu setelah Alquran. Ketiga, mengingkari kebenaran Alquran dan Hadis Nabi Muhammad SAW. Keempat, melakukan penafsiran Alquran yang tidak berdasarkan kaidah-kaidah tafsir. Kelima, mengingkari kedudukan hadis Nabi Muhammad SAW sebagai sumber hukum Islam. Keenam, melecehkan, menghina, dan merendahkan para Nabi. Ketujuh, mengingkari Nabi Muhammad SAW sebagai nabi rasul serta penutup para nabi dan rasul di akhir zaman. Kedelapan, mengubah, menambah atau mengurangi pokok-pokok ibadah yang telah ditetapkan syariat, seperti ibadah haji tidak ke Makkah. Kesembilan, mengingkari kewajiban salat fardhu. Kesepuluh, mengkafirkan sesama muslim tanpa dalil syar'i, seperti; mengkafirkan muslim hanya bukan kelompoknya. Jika suatu aliran memiliki salah satu dari kriteria tersebut di atas, maka dianggap menyimpang dari ajaran agama serta ditetapkan sebagai aliran sesat." (Tajuk Rencana, Riau Pos Jumat 22 Januari 2016)

Pengakuan yang serupa juga terlontar oleh penanggungjawab rombongan, Sukino Hasbi mengungkapkan organisasi yang diikutinya bukanlah keagamaan, namun sosial. Di mana pemahaman dan pola pikir tentang agama dan kehidupan sosial sangat berbeda jauh dengan umat Muslim di Tanah Air.

"Islam Anda dan saya beda. Kalau
salat, banyak juga yang tak salat.....
Orang yang memandang kami
miring, kalaukatanya kami bukan
Islam kebanyakan, memang bukan.
Islam kami beda, kami tunduk
patuh, mengabdi hanya kepada satu
Tuhan, sesuai Pancasila. Itu sudah
jelas dan tegas...... Kami tidak
bedakan agama, semua kami
rangkul di Gafatar. Anggapan
orang-orang miring terhadap kami.
Kami bukan keluar dari Islam, tapi
keluar dari paham Islam
kebanyakan."(Riau Pos, 9 Febuari
2016)

Dalam pembinaan, perlu dikontrol dengan baik dan teratur mengenai pemahaman dan pola pikir tentang agama dan kehidupan sosial yang sesuai dengan falsafah bangsa dan agama islam di Tanah Air. Khusus anak-anak Ketua P2TP2A Riau Risda mengatakan pihaknya akan melihat tingkat trauma pada anak-anak sejauh mana doktrin yang akan diberikan, dan perbaikan akan dilakukan 
supaya bisa dikembalikan seperti anak-anak kebanyakan. Ia berkomitmen akan mendampingi hingga tuntas, seluruh anakanak yang tergabung dalam pengungsi Eks Gafatar Riau. Bahkan jika diperlukan sampai ke kabupaten/kota akan dilakukan nantinya. Supaya anak-anak yang cukup banyak dapat dididik kembali sesuai norma dan syariat agama serta sosial masyarakat Riau khususnya.

"Dilihat usia, jumlah, dan sejauhmana traumanya, baru bisa dikuatkan treatmen. Permainan dan mengubah mindset. Kami akan pelajari, bahan awalnya, kalau bisa ditindaklanjuti, psikolog akan disiapkan, karena akan kelihatan dari bermain, hasil akhir kami akan rekomendasikan, siapa melakukan apa," beber Ketua P2TP2A Riau. (Epaper Riau Pos, Selasa 9 Febuari 2016)

\section{Hasil Analisis Representasi Pemberitaan Pemulangan Eks Gafatar di Surat Kabar Riau Pos}

Dalam pemberitaan pemulangan eks Gafatar Riau Pos lebih merepresentasikan menggunakan constructionist approach Pendekatan ini tidak berarti bahwa kita mengkonstruksi arti (meaning) dengan menggunakan sistem representasi (concept dan signs), namun lebih pada pendekatan yang bertujuan mengartikan suatu bahasa (language) yang mudah dipahami. Berikut constructionist approach yang digunakan dalam pemberitaan diatas yaitu :

- Pendekatan yang menggunakan sistem bahasa (language) yang mudah dipahami karena dengan menggunakan bahasa sehari-hari dan pemberitaan yang minim: baik dari segi layout penempatan berita yang kecil dan foto peristiwa memberikan kesan terselubung untuk menyampaikan berita ini. Tanggungjawab yang lebih mengarah pada tindakan pejabat terhadap kasus tersebut hingga deskripsi yang menjadi ilustrasi disampaikan oleh Riau Pos.

- System apapun untuk merepresentasikan konsep kita (concept) dengan menyampaikan perkembangan berita yang disampaikan oleh pejabat yang berwenang memberikan nilai positif bagi kinerja pemerintah khususnya Riau bahwa pemerintah menjamin bertanggungjawab penuh dalam keberadaan mereka yang sudah terawasi dan tertangani. Hal ini bisa saja sebagai bentuk kontrol sosial yang dilakukan oleh media terhadap masyarakat riau. Riau Pos menekankan eks gafatar sebagai ancaman terhadap masyarakat melalui ajaran yang mereka anut. Ia Justru mencoba untuk menumbuhkan kepercayaan pembaca terhadap kinerja aparat pemerintah dalam mengawasi dan menangani kasus tersebut.

Riau Pos merasa tidak perlu takut untuk ditinggalkan atau dianggap berpihak pada pemerintah. Mereka tetap berpegang teguh dengan agenda yang telah mereka sepakati secara kolektif sebagai sebuah media. Agenda tersebut tetap akan sampai ke masyarakat bahkan sudah sampai ke masyarakat melalui media yang lebih unggul dari sisi timeless seperti tv dan portal. Berita Riau Pos tidak menapik dari peristiwa yang ada namun mereka lebih menyanjung prinsip wisdom yang tertanam dalam ideologi mereka. Menjaga citra pemerintah sekaligus negeri.

\section{KESIMPULAN}

Dari hasil penelitian representasi pemberitaan pemulangan eks gafatar di surat kabar Riau Pos menggunakan analisis wacana Van Dijk disimpulkan bahwa:

1. Analisis wacana, pemberitaan di surat kabar Riau Pos mengedepankan tema 
yang mengangkat tentang perjalanan penanganan yang dilakukan oleh pemerintah Riau dalam mengawal pemulangan eks gafatar ke Riau. Penekanan pada kinerja aparat pemerintah melalui pembinaan yang dijanjikan diupayakan Riau Pos guna menumbuhkan kembali kepercayaan masyarakat untuk dapat menerima kembali mereka di lingkungan masyarakat dengan jaminan dari pemerintah

2. Representasi media yang dilakukan oleh Riau Pos yang menggunakan constructionist approach yang dinilai berpihak kepada pemerintah sebagai bentuk menumbuhkan kepercayaaan pemerintah dalam menangani kasus tersebut. Tanpa terkesan menyembunyikan peristiwa tersebut, Riau Pos mencoba menekan konflik dengan memberikan peran kontrol sosial ke pada masyarakat.

\section{DAFTAR PUSTAKA}

Alwasilah, Chaedar. A. 2002. Pokoknya Kualitatif (Dasar-dasar Merancang dan Melakukan Penelitian Kualitatif). Jakarta: Dunia Pustaka Jaya.

Barus, Sedia Willing. 2010. Jurnalistik, Petunjuk Teknis Menulis Berita. Jakarta: Erlangga

Eriyanto. 2011. Analisis Wacana: Pengatur Analisis Teks Media.Yogyakarta: LKiS.

Hasfi, Nurul, 2011, Analisis Framing Pemberitaan Malinda Dee Di Detikcom, Majalah Tempo dan Metro TV, Jurusan Ilmu Komunikasi Fakultas Ilmu Sosial Dan Ilmu Politik Universitas Diponegoro.

Littlejohn, Stephen W. 1996. Theories of Human Communication. Fifth Edition. Belmont, California: Wadsworth Publishing Company.
Lubis, A. Hamid Hasan. 1993. Analisis Wacana Pragmatik. Bandung: Angkasa.

Mayasari,Tri. 2016,Perbandingan Pemberitaan Dahlan Iskan Terkait Kasus Tersangka Dugaan Korupsi Gardu Induk Di Surat Kabar Riau Pos, Jurusan Ilmu Komunikasi Fakultas Ilmu Sosial Dan Ilmu Politik Universitas Riau

Moleong J. Lexy. 2004. Metode Penelitian Kualitatif. Bandung: Remaja Rosda Karya.

Nimmo, Dan. 1993. Komunikasi Politik Khalayak dan Efek, Penerj. Jalaluddin Rakhmat, Bandung, Rosdakarya

Sudibyo, Agus. 2001. Politik Media dan pertarungan Wacana. Yogyakarta: LKIS

Suhandang, Kustadi. 2004. Pengantar Jurnalistik Seputar Organisasi, Produk dan Kode Etik. Bandung: Yayasan Nusantara Cendekia

Sobur, Alex. 2006. Analisis Teks Media, Suatu Pengantar Analisis Wacana, Analisis Semiotik, dan Analisis Framing. Bandung: Rosdakarya.

\section{Sumber-Sumber lain:}

Epaper Riau Pos, 22 Januari 2016-11 Febuari 2016

Mukhtarudin, Organisasi Terlarang dan Aliran Sesat; Tajuk Rencana, Riau Pos, Jumat, 29 Januari 2016.

Masrizal Al Husyaini,Waspadai Aliran Sesat, Tajuk Rencana, Riau Pos Jumat 22 Januari 2016 
